\title{
Expansive Concretes for Shotcrete in Tunnel Construction
}

\author{
Igor Kharchenko ${ }^{1}$, Alexander Panchenko ${ }^{2,}$, and Aleksey Kharchenko ${ }^{3}$ \\ ${ }^{1}$ Department of design, Moscow State University of Civil Engineering,26, Yaroslavskoye Chausse, \\ Moscow, Russian Federation \\ ${ }^{2}$ Chair of binding agents and concrete, Moscow State University of Civil Engineering, 26, \\ Yaroslavskoye Chausse, Moscow, Russian Federation \\ 3"Planeta K” LLC, 143132, Moscow, Russian Federation
}

\begin{abstract}
This paper presents the results of investigation of properties of fine-grained concrete on expansive cement for fiber-reinforced shotcretes used for metro tunneling. Basic factors affecting material expansion after mixing with water are described. The influence of expansive components on the values of strength indices and volumetric deformations of shotcrete is studied. Improvement of process, physical and mechanical, and operational characteristics of obtained shotcrete is proven.
\end{abstract}

\section{Introduction}

At the present time at construction of tunneling the shotcrete technology is widely applied [1], which provides for conveying of the concrete mix via pipes or hoses with further application onto concreted surface under high pressure via special taps. This requires minimum expenditures for organization of construction site and excludes expenditures for formwork activities [2].

Despite its economic attractiveness shotcrete technology assumes strict requirements to concrete mix quality that to a large extent is defined with optimally selected and strictly repeatable composition of coarse and fine fillers [3-5]. However, in Russia practice of procurement of multiple-size aggregates necessary for obtaining of qualitative mix is absent. This is in the first place related to the fact that the suppliers of fillers look up to the existing regulatory environment, where fillers have a relatively "rough" sizing $(5 \ldots 10 \mathrm{~mm}$, $10 \ldots 20 \mathrm{~mm}$ etc.), which allows for substantial variation of percentage ratio of separate fractions even within the frames of delivery of separate batches. This excludes a possibility of their application for preparation of high-quality shotcrete. Concurrently, particle size distribution of supplied quartz sand is sufficiently stable and reproducible. In this connection, to our opinion, both in Russia and in the majority of other countries the most promising for shotcrete is the application of mixes on the basis of non-chipping finegrained concretes. Herewith, one of the essential factors restricting wide application of fine-grained concretes in construction practice is their low crack resistance due to the

\footnotetext{
${ }^{*}$ Corresponding author: alex250354@gmail.com
} 
development of shrinkage strain stipulated with a substantial content of binder in the concrete mix composition.

At designing of shotcrete composition it is necessary to account for several features: necessity of provision of high fluidity and connectivity of concrete mix in order to minimize its loss due to rebound during spraying, necessity of provision of sufficiently high indices of early strength during the period of up to 24 hours and final strength of concrete, increased deformability of concrete, which reduces the risk of brittle fracture of tunnel lining structures. These requirements to a certain degree contradict one another: provision of high strength indices and the necessity of high deformability in order to eliminate brittle fracture. This contradiction is eliminated by means of adding fiber to shotcrete composition, optimally selected grain-size distribution of fillers and application of expanding additives allowing shrinkage compensation and increase of shotcrete crack resistance [6-8].

In order to improve fine-grained shotcrete quality at chair of binders and concretes of MGSU is performed a comprehensive research on the development of methods of reduction of unfavorable effect of shrinkage strain on the basis of application of multiplefunction expanding additives prepared using commercially available components and introduced to concrete mix composition during its preparation at the construction site. Herewith, expanding additives introduced to shotcrete composition have different functional manifestation at different stages of forming of its structure and properties [6]. Thus, at introduction to concrete mix composition of finely-dispersed expanding additive is provided its distribution in intergranular space of basic Portland cement displacing water and reducing actual value of W/C. Herewith connectivity of mix is substantially increased at simultaneous increase of its fluidity and workability, which substantially minimizes losses due to rebound. Besides, displacing of excessive water from intergranular space of basic Portland cement, as well as distribution of expanding additive grains in it, performing the function of stabilizing frame, reduces the value of shrinkage strain. Further, during development of hydration process, in addition to the factor of free water displacement, ettringite formation is accompanied by the increase of volume of hardening cement stone compensating the shrinkage [8]. Besides, intense formation of ettringite at hardening of expansive additive provides achieving by concrete of required early strength.

Important criterion of assessment of quality of reinforced concrete lining of tunnel structures is their crack resistance. Known method of improvement of crack resistance of reinforced concrete structures is tendon pretension. However, during construction of tunnels of cast reinforced concrete it is impossible to provide tendon pretension with conventional methods. In this connection an effective solution for problem of improvement of crack resistance of reinforced concrete structures is the implementation of expansive cements, which hardening is followed by the release of chemical energy sufficient for concrete prestressing due to pretension of tendons inside the structure body [9]. In construction practice these structures are called self-stressing reinforced concrete structures, and expansive cements used for these purposes are called self-stressing cements.

Cement with time-controlled value of expansive effect was for the first time developed by A. Guttmann in 1920, which was designated as "shrinkage-compensating cement" or "non-shrinking cement" [10]. These terms are also applied nowadays, which to a great extent also defines their application in construction. Thanks to studies of professor V.V.Mikhaylov the expansive cement got further development as "self-stressing cement", because at its hardening is provided a prestressing of tendon located within the reinforced concrete structure. At designing of reinforced concrete structures on the basis of "selfstressing cements" all known calculation procedures that are applied at designing of 
standard prestressed reinforced-concrete structures with the account of design and process features are applicable [9].

Essential technological advantages as compared to industrial production of expansive cements are pertinent to those cements that are manufactured directly at the construction site or at a concrete plant by means of mixing of ordinary Portland cement with expanding components at preparation of concrete or grout [11-14]. This method of production of expansive concrete is the easiest and the most available one and attracts considerable interest in many countries.

Comparative analysis of construction and technical properties of concretes on the basis of expansive cements with different types of expanding additives demonstrated that the highest stability of properties providing control of expansion processes, forming of structure and properties belong to expansive cements on the basis of ettringite formation [15-18].

\section{Methods}

In order to evaluate the degree of practical feasibility of different expanding additives for obtaining of reinforced concrete structures produced according to the shotcrete technology, a research of properties of expansive cements with expanding additives on the basis of calcium sulfoaluminate was conducted.

During experimental research the specimens were manufactured with the size of $40 \times 40 \times 160 \mathrm{~mm}$ and $70 \times 70 \times 280 \mathrm{~mm}$ made of fine-grained concrete mix with $\mathrm{C} / \mathrm{S}$ $($ Cement/Sand $)=1: 2$ at $\mathrm{W} / \mathrm{C}=0,4$.

Belgorod Portland cement with the activity of 52,4 MPa, with normal thickness of $25,5 \%$, real density of $3,1 \mathrm{~g} / \mathrm{cm}^{3}$ and specific surface of $3450 \mathrm{~cm}^{2} / \mathrm{g}$ was used as binder. Quartz sand with fineness modulus $\mathrm{Fm}=2,2$, with real density of $2,45 \mathrm{~g} / \mathrm{cm}^{3}$ and bulk density of $1,58 \mathrm{~kg} / \mathrm{l}$ was used as filler.

A mix of high-alumina cement "Secar -70" and activated metakaolin with anhydrous plaster in stoichiometric ratio required for complete formation of ettringite was used as expanding additive. Content of the expanding additive in composition of basic Portland cement was 5\%;10\% and $15 \%$. After preparation the specimens were cured for 28 days at relative humidity of $100 \%$ with further placement to moisture-free conditions at relative humidity of about $60 \%$. WIRANDFS7 fiber with consumption of $25 \mathrm{~kg} / \mathrm{m} 3$ was used as steel fiber. S12R polypropylene fiber with consumption of $1,2 \mathrm{~kg} / \mathrm{m} 3$ was used as polypropylene fiber.

\section{Results and Discussion}

Intense expansion process was demonstrated by all expansive cements during first $48 \ldots 72$ hours of hydration (fig.1). After that the value of expansion slightly increases at further hardening during 28 days in tight conditions. In several cases is recorded a drop of compression strength, which is theoretically explained by the destruction of cement stone internal structure.

In the case of storage under normal conditions the effect of after-expansion manifests itself only in the case of content of expanding components in the quantity of not less than $10 \%$, after occurrence of all shrinkage deformations. Expansive cements containing up to $5 \%$ of expanding components at storage in the air for a period of up to 28 days have final value of shrinkage substantially less than the common Portland cement. The research demonstrated that the properties of expansive cements with expanding additives on calcium sulfoaluminate basis depend both on mass correlation between Portland cement matrix and content of expanding components, as well as on their activity. [16-18]. 


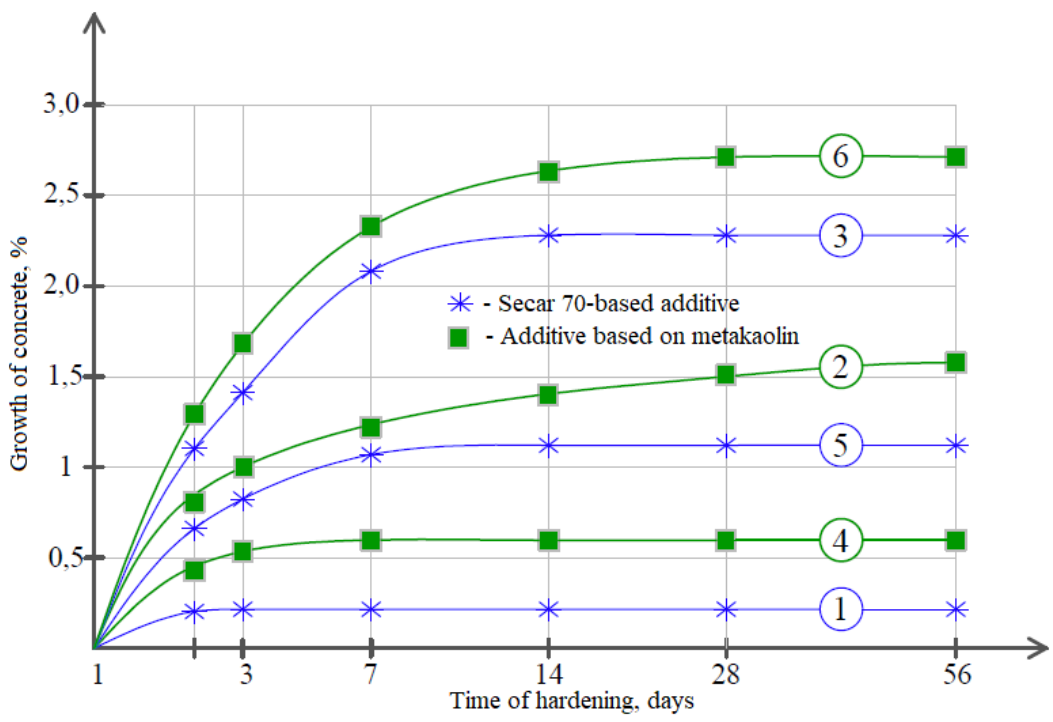

Fig. 1. Kinetics of fine-grained concrete expansion depending on the type and quantity of expanding additive: 1 and 4; 2 and 5; 3 and 6- expanding additive content of 5\%;10\% 15\%, respectively.

The analysis of the results of research of properties of expansive cements and concretes on their basis, as well as of products of their hydration did not allow establishing of correlation dependence between the expansion value and the quantity of formed ettringite. It was established that in certain cases expansive cements, at which hydration more ettringite is formed, demonstrate lesser degree of expansion than cements with less formed ettringite. This is explained with the degree of kinetic matching between the intensity of hardening of Portland cement matrix and ettringite formation [18]. On the basis of the analysis of the results of experimental research it is established that for the same initial components the increase of volume of expansive cements is proportional to the increase of content of expanding components in cements with correlation factor of 0,83 . The properties of expansive cements prepared under conditions of the construction site are significantly influenced by such factors as mineralogical composition and dispersion ability of Portland cement. The research of expansive cements on the basis of 50 Portland cements from different cement plants demonstrated that the most stable and predictable construction and technical properties of expansive cements are achieved at application of Portland cements with $\mathrm{C} 3 \mathrm{~A}$ content of up to $5 \%$. Herewith was established an essential regularity, according to which with the increase of dispersion ability of expanding component the value of expansion decreases, and, on contrary, compression strength and expansion pressure increase. Besides, as the result of experimental research was established the dependence between $\mathrm{A} 12 \mathrm{O} 3$ / SO3 - correlation of expanding components and the value of expansion. For instance, at the increase of correlation from 0,5 to 1,5 the value of expansion decreases from 2 to $0,5 \%$. Analysis of kinetics of strength development demonstrated that the compression strength intensely grows after decaying of expansion process during the period of up to 28 days. (fig. 2). Herewith, final value of expansion is considerably higher at storage under water than at storage at normal temperature and humidity conditions, excluding development of moisture shrinkage.

Considering obtained results in whole it is possible to make a conclusion that the application of expanding additives in fiber shotcrete provides the decrease of shrinkage strain with the respective increase of crack resistance and durability. 


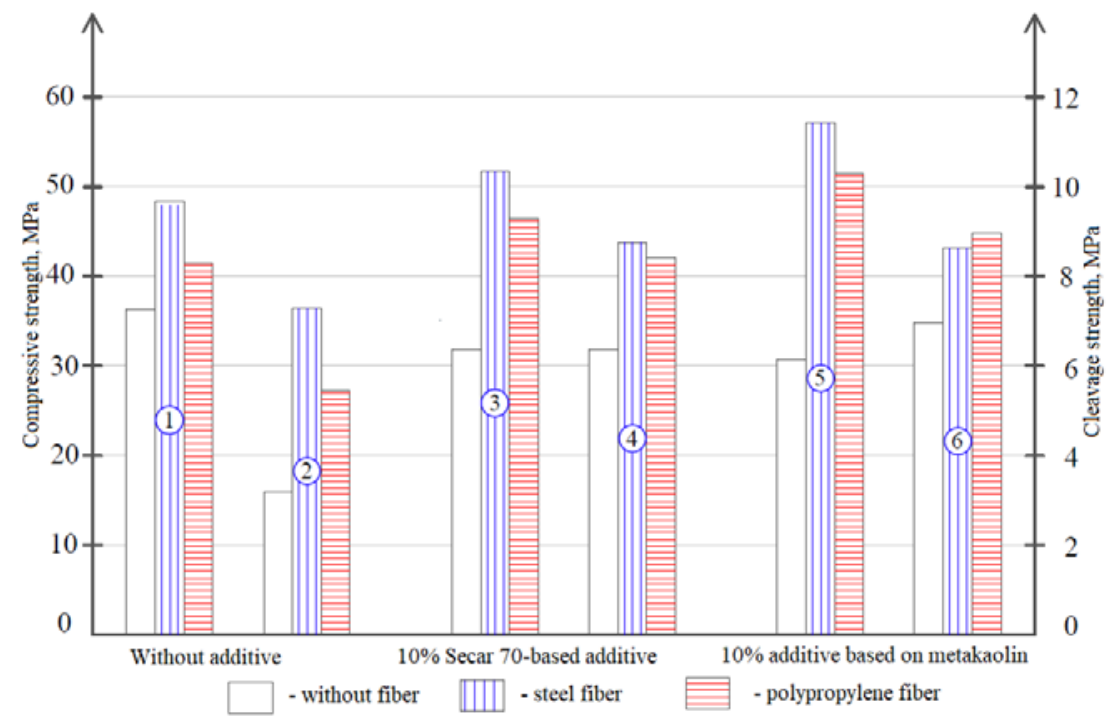

Fig. 2. Kinetics of strength development for fine-grained concrete with the expanding additives and steel (polypropylene) fiber.

The decrease of shrinkage strain takes place at the expense of taking by the fibers of tensile stress and forming of a fiber cage, acting as mechanical restraint for expansion strain and causing compressive stress in the concrete matrix providing improvement of structure crack resistance in whole. Implementation of the effect of expansion and shrinkage compensation is especially effective at construction under severe geotechnical and operating conditions.

The experiments proved that at "free" expansion the strength is reduced along with the increase of expansion degree growth. This is a consequence of structure destruction at the development of two oppositely acting processes - strengthening of PC-portion and increase in volume at expanding additive hydration. Moreover, at further storage under the water, e.g. for a period up to 6 months, expansive cements strength is from 10 to $30 \%$ higher than the compressive strength of basic Portland cements used as matrix. It is established that at hardening of expansive cements the feature of their structuring is in the fact that at fixed $\mathrm{B} / Ц$ an essential effect on the strength of cement stone and concrete on its basis, its value and magnitude and the behavior of pore structure is caused by the apparent expansion degree (fig. 3).

In the case of intense hardening of Portland-cement matrix, depending on the expanding components activity, the ettringite crystallizes in cement stone pores, reduces their volume and size and densifies capillary-porous structure. Herewith the expansion is negligible $(<0,1 \%)$. Along with the growth of crystallizing ettringite its free formation in pores is inhibited; as the result, in cement stone structure inherent stress appears. In this connection the apparent expansion deformations increase up to $0,4 \ldots 0,7 \%$, and the quantity and the size of pores is reduced. At achieving of critical stress, e.g., due to further increase of quantity of formed ettringite, inherent stress in Portland-cement matrix structure increases as well. Surpassing of critical value of tensile stress first of all shows itself in formation of internal cracks in cement stone, which points to the increase of total porosity and the increase of portion of large pores. At further development of expansion process additionally external cracks appear, and the process of self-destruction of cement stone structure takes place. In this case, total porosity index increases up to $20 \%$ and more. (fig. 3). 


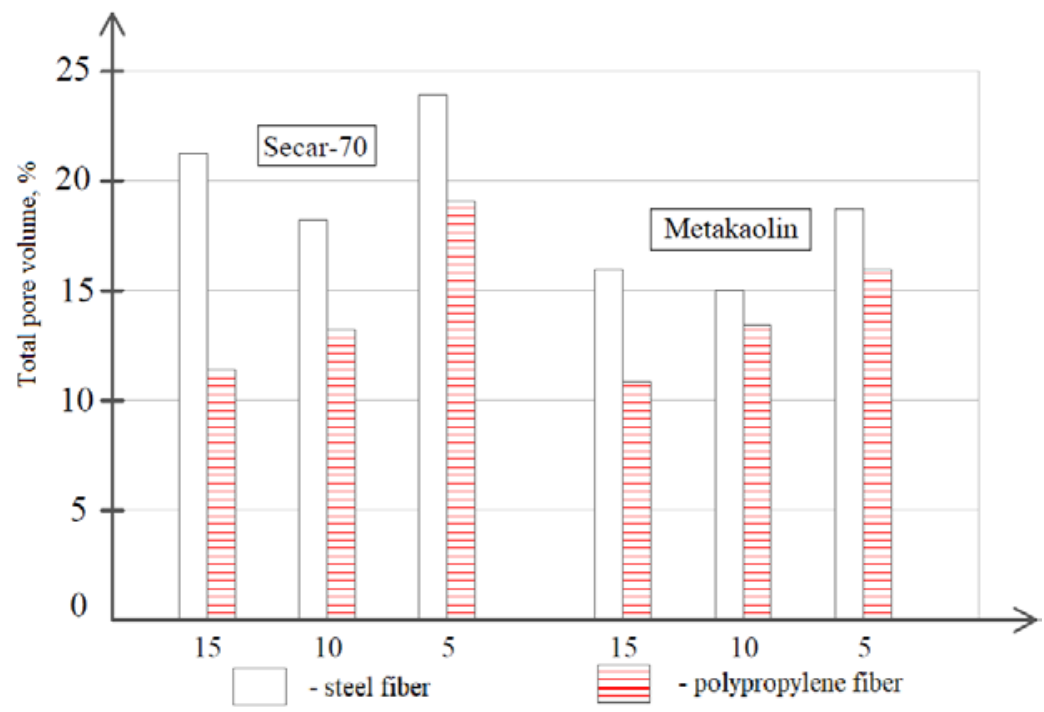

Fig. 3. Total porosity of fine-grained concrete on the basis of expansive cement depending on the type and quantity of the expanding additive: - steel fiber; - polypropylene fiber

With the reduction of Portland-cement matrix hardening intensity and with the increase of expansive components activity increases the portion of ettringite, which is crystallized not only in pores thus causing their densifying, but also partially in the gel phase of hardening Portland cement matrix without development of inherent stress causing formation of cracks. As a consequence, cement stone has dense and fine-pored structure, as well as the concrete on its basis.

As a numerical criterion allowing classification of the whole variety of expansive cements applied in construction practice the correlation between the strength change and the expansion deformation in active structuring phase may be considered. It is proposed to consider this criterion as a quality coefficient for expansive cements $\mathrm{Kq}$, which is determined as follows:

where:

$$
K q=V d / V e=(\beta w-\beta l) / \beta l:(L w-L l) L l,
$$

$V d$ - is the gain of compression strength at curing in 24 hours;

$V e$ - is the value of linear expansion at curing in 24 hours;

$\beta l ; L l$ - are the compression strength and the length of cement prism 24 hours after hardening in a mold under air-tight conditions at $22^{\circ} \mathrm{C}$, respectively;

$\beta w ; L w-$ are the corresponding indices after completing of hydrothermal treatment at $35^{\circ} \mathrm{C}$ during 24 hours, respectively.

Thus, the coefficient Kq characterizes the correlation between the kinetics of strength gain and expansion intensity in active structuring phase at hardening of expansive cement, which may be considered as one of basic characteristics of expansive cements. On the basis of the research results analysis for expansive cements pore structure with different values of apparent deformations a regularity was found between the characteristics of pore space and quality coefficient Kq. On this basis it becomes possible to classify almost all types and kinds of expansive cements into at least three groups: type 1 with $\mathrm{Kq}<10$; type 2 with $10<\mathrm{Kq}<100$ and type $3 \mathrm{Kq}>100$.

With due account for high potential of expansion of cements of type $1(\mathrm{Kq}<10)$, at hardening of concretes it is necessary to provide for a possibility of restriction of expansion process. The most effective area of application of these cements in construction 
may be, e.g., sealing of joints in tunneling structures at provision of complete impenetrability and firm joints of construction elements. Herewith due to restriction of expansion deformation the formed ettringite is located in pore space of hardening cement stone and concrete, densifies it and provides a reliable contact of mounted equipment with the base. Expansive cements of type $2(10<\mathrm{Kq}<100)$ may be applied in reinforced concrete structures, where expansion deformation is taken by tendons within the concrete. In this case tendon prestress developed uniformly within the volume is provided, i.e. threeaxis tendon prestress is formed at the expense of chemical energy released at hardening of self-stressing cement. In this case a combination of steel fiber and expansive cement for manufacturing of reinforced concrete tunnel lining allows full-extent implementation of all potential possibilities of spacious self-stressed reinforced concrete structures. Russia has a design and application experience of so called self-stressing reinforced concrete structures, which in fact is the only way of tendon three-dimensional pretension. Expansive cements of type $3(\mathrm{Kq}>100)$ may be applied instead of standard Portland cements, if it is necessary to eliminate the shrinkage impact on impenetrability, durability and other important characteristics of concrete and reinforced concrete structures of tunnel lining.

\section{Conclusions}

It was established that the expansion degree, the porosity and the strength characteristics of expansive cements are to a great extent defined with the correlation between the rate of strength gain by Portland cement matrix and the rate of ettringite formation.

In order to implement all possible capabilities of expansive cements at their practical application for lining of tunnel structures using shotcrete it is necessary first of all to account for three factors: rate of Portland cement matrix hardening, hydraulicity of expanding components and quantitative correlation between the Portland cement matrix and expanding additive. Depending on the degree of correlation of these parameters it is possible to obtain expansive cements that demonstrate different expansion values and, respectively, affect basic properties of expansive cements and concretes.

Application of expansive cements in combination with steel fiber allows provision of spatial self-stressing of reinforced concrete structures of tunnel lining at the expense of chemical energy released at their hardening.

\section{References}

1. V.A. Alekseev, S.I. Bazhenova, I.Ya. Kharchenko, A.I. Kharchenko, S.A. Kryvchun, Housing construction, Improvement of quality of shotcrete for construction of tunnel and near-tunnel structures No. 9, pp. 33-36 (2016)

2. V.A. Alekseev, I.Ya. Kharchenko, A.I. Kharchenko, S.I. Bazhenova, A.S-E. Beterbiev, Vestnik MGSU, Modified concrete mixes for three-dimensional structures applied with the shotcreting method, No. 11, pp. 48-58 (2016)

3. X. Zhang, Z. Liu, F.Wang, Constructions and Buildings materials, Autogenous shrinkage behavior of ultra-high performance concrete, 226, pp. 459-468 (2019)

4. F. Pelisser, A.B. Neto, H.L.L. Rovere, R.C. Pinto, Construction and Building Materials, Effect of the addition of synthetic fibers to concrete thin slabs on plastic shrinkage cracking) 24(11), pp. 2171-2176. , (2010)

5. J. Gong, W. Zeng, W. Zhang, Construction and Building Materials, Influence of shrinkage-reducing agent and polypropylene fiber on shrinkage of ceramsite concrete, 159, pp. 155-163 (2018) 
6. M. S. Elsufieva, V. G. Soloviev, A. F. Buriyanov, Construction Materials, Application of expanding additives in steel-fiber concrete, No. 8, pp. 60-63 (2014)

7. V. G. Soloviev, A.F. Buriyanov, M. S. Elsufieva, Concrete Technology, Ways to improve the production efficiency of prefabricated steel fiber-reinforced concrete products, No. 1, pp. 34-36 (2016)

8. M. S. Elsufieva, V. G. Soloviev, IV International Scientific Conference. Moscow, Create Space Independent Publishing Platform, Getting stalefibrobetone with compensated shrinkage. Actual directions of fundamental and applied research, pp. 160-164 (2014)

9. V. V. Mikhaylov, S. L. Litver, Expansive cements, self-stressing cements and selfstressed reinforced concrete structures, p. 311 (Stroyizdat, Moscow, 1974)

10. A. Guttmann, DRP Nr. 330784 vom 29.01.1920, Verfahren zur Herstellung schwindfreien Betons, (1920)

11. P. Carballosa, J. L.García Calvo, D. Revuelta et al., Construction and Building Materials, Influence of cement and expansive additive types in the performance of self-stressing and self-compacting concretes for structural elements, v. 93, pp. 223229 (2015).

12. M.Yu Titov, Construction Materials, Concretes with increased strength on the basis of expanding additives, 2, pp. 84-87 (2012)

13. I. Janotka, F. Puertas, M. Palacios et al., Construction and Buildings Materials, Metakaolin sand-blended-cement pastes: rheology, hydration process and mechanical properties v. 24, pp. 791-802 (2010).

14. P. Carballosa, J.L. García Calvo, D. Revuelta et al., Construction and Building Materials, Influence of cement and expansive additive types in the performance of self-stressing and self-compacting concretes for structural elements, v. 93, pp. 223229 (2015)

15. T. Apih, G. Lahajnar, A. Sepe, et al., Cement and Concrete Research, Proton spinlattice relaxation study of the hydration of self-stressed expansive cement, v. 31. Issue 2, pp. 263-269 (2001).

16. A. Pantschenko, 14 ibausil. Internationale Baustofftagung, Eigene Deformationen und Dauerhaftigkeit von Beton, Band 2, ss. 689-69 (2000)

17. A. Panchenko, Yu. Bazhenov, I. Kharchenko, Durability and sustainability of concrete structures. DSCS-2018. Proceedings 2nd International Workshop, Durability of the concrete based on a sulphate-aluminate cement. Moscow, Russia. SP-326. 33.1-33.9. (2018)

18. A.I. Panchenko, Cem. Concr. Res., Control of expansion and structure formation of expansive cement, v. 20, pp. 602-609 (1990) 